\title{
Social Work Education For Aboriginal Communities
}

\section{LESLIE A. BROWN ${ }^{\star}$}

\begin{abstract}
This paper examines aboriginal social work education in Canada and suggests that current education practice may be facilitating the assimilation of aboriginal students into a mainstream culture and profession. Developments in aboriginal social work programs and curriculum are reviewed and a philosophy of recognition and accommodation of aboriginal perspectives as a basis for future developments is posed as an alternative to assimilation. Further, a strategy for teaching, termed interface teaching, is suggested as a way in which non-aboriginal educators can take individual responsibility for wrestling with some of the issues that arise in the professional education of aboriginal students.
\end{abstract}

\section{Résumé}

Cet article examine la formation des travailleurs sociaux autochtones au Canada et suggère que la pratique actuelle de formation pourrait promouvoir l'assimilation des étudiants autochtones dans le courant dominant de la culture et de la profession. Les développements récents des programmes d'étude conçus pour les autochtones dans le domaine du travail social ont été examinés et une philosophie de reconnaissance et d'accommodation des points de vue autochtones comme base de développement futur est proposée come alternative à l'assimilation. De plus, une stratégie d'enseignement, appelée enseignement par interface, est suggérée pour permettre aux éducateurs non-autochtones de répondre de façon individualisée et responsable aux problèmes soulevés par la formation professionelle des étudiants autochtones.

Over the past decade, Canadian schools of social work have been exploring ways and means of responding to the expressed interests of aboriginal communities in relevant professional social work education leading to degrees (Castellano, Stalwick \& Wein, 1986; University of Victoria, 1990; Pace \& Smith, 1990). While program development is occurring, there is a concurrent need to reflect on what social work knowledge has to offer these communities

*University of Victoria 
and to examine the teaching behaviours of the predominantly non-aboriginal group of social work educators. The intent of this paper is to reflect on current efforts in social work education; and to suggest that, without such consideration and subsequent change, the experiments in aboriginal social work education will serve primarily to absorb aboriginal people into the dominant culture. Further, non-aboriginal teachers have the responsibility and opportunity to examine teaching behaviours in the classroom and to consider their role in educating aboriginal social workers.

Social work education is an assimilative process for all students. Through the teaching of social work knowledge, skills and values, students are acculturated into the profession. While individual difference is recognized and respected in the profession, a common philosophy and purpose is central to the definition of ethical social work practice. This philosophy is firmly rooted in the non-aboriginal cultural experience in Canada and the United States. Graduating students are expected to share a common approach to viewing problems and solutions within this cultural context. Thus, social work educators face a formidable challenge: how to encourage a commitment on the part of aboriginal students to their profession and its philosophy, without at the same time attempting to assimilate them into the dominant values of non-aboriginal society.

This challenge is not impossible to resolve if the profession and educators are open to reviewing, with aboriginal peoples, how the profession's view of its philosophy, values, goals and methods might change, if at all, as these are applied to different aboriginal communities. Recognition of the uniqueness of aboriginal peoples and social work practice, as well as the accommodation, not assimilation, of aboriginal perspectives in contemporary Canadian professional social work, may begin to respond to this challenge.

Different views about social work practice and education have been pondered. Castellano, Stalwick and Wien argue that social work values are congruent with aboriginal values. In their opinion, it is the practice, not the values, of social work in aboriginal communities that requires adaptation. Pace and Smith do not agree. Through the outline of their experience in adapting curriculum, they assert that mainstream social work theory and values require challenge. Similarly the University of Victoria's First Nations initiative, among others, has determined that there is a necessity for some adaptation of content. Aboriginal students facilitate such actions by continuing to remind educators to what extent the social work educational experience is meeting their learning needs (Douse \& Green, 1990). There is general agreement that something needs changing; that traditional non-aboriginal social work education cannot be simply transplanted into an aboriginal educational context. 
Perceptions of the nature of the incongruity, however, range from fundamental value differences, to the institutional context within which education occurs (alienating systems), to course content. Such perceptions are particular to the individual students, the educators and the communities involved. How, if at all, can social work education be altered to reconcile the incompatible aspects of values, knowledge and skills that arise when that education is placed in the context of an aboriginal community? Social work programming models, curriculum and teaching models beg critical reflection.

\section{Models of Programs}

There are various models of aboriginal social work education in operation across Canada. Developments of these models generally take one of two directions: distinctive or integrative. Distinctive programs focus specifically on aboriginal students, involving aboriginal communities in various ways in program development. Integrative developments are seen in those schools which find increasing numbers of aboriginal students in their regular classes, and thus have curriculum questions regarding aboriginal perspectives arise in ongoing reviews.

Marlene Castellano and her colleagues articulated different program models typical of Canadian institutions, that reflected various means and degrees of aboriginal control. First, the autonomous programs, such as the Nicola Valley Institute of Technology in Merritt, B.C., are distinctive and are the most independent of non-native influence. Second, those affiliated with an existing non-aboriginal institution, such as the Saskatchewan Indian Federated College program, are distinctive in that they are designed by, and intended for, aboriginal peoples. Third, special aboriginal programs created by non-aboriginal institutions, such as the MicMac B.S.W. program at Dalhousie, are also distinctive in that they are developed for aboriginal students.

These models of programs tend to be regarded as more responsive than integrative models to the needs of the aboriginal communities they serve. Conventional models such as the regular on-campus program at the University of Victoria are integrative in that course content, teaching approaches and practicum opportunities are being continually reworked in order to respond to the interests of an ever-increasing aboriginal student body. ${ }^{1}$ The integrative programs are not grounded in aboriginal communities; rather they attempt to accommodate the particular needs of aboriginal students within conventional educational practice. 
Whether distinctive or integrative, the question remains: how can such a potentially conflicting duality in educational initiatives be managed? Cassidy and Bish (1989) note:

This duality of recognition and assimilation...is mirrored in the reserve system created by federal and provincial legislation. Starting in 1830 , Indian settlement on reserves began under government guardianship. Reserve lands were set apart for Indians in recognition of their separateness. Reserves were also established as a way of assimilating Indian people into property relationships and civil order of Canadian society.

This issue of recognition and assimilation may be paralleled in some models of aboriginal education. The distinct aboriginal social work education initiatives that have been established recognize the uniqueness and separateness of aboriginal peoples. They have some advantages over integrative programs in that they are, or can be, closer to the communities they serve and perhaps more able to be influenced by First Nations than by non-aboriginal parent institutions. Conversely, they may be seen as just more subtle than integrative programs in assimilating aboriginal students into a traditionally non-aboriginal way of thinking and working (i.e., professional social work).

Integrative programs offer opportunities to individual educators. Without launching a major institutional initiative or awaiting a departmental directive, individual teachers can respond to the interests of their current students. On the negative side, integrative approaches may not be desirable because multicultural or cross-cultural social work, rather than social work in aboriginal communities, can become the central theme. While having aboriginal students in the classroom helps learners to grapple with the whole theme of diversity and difference, this is not necessarily as important to aboriginal social work students as it is to non-aboriginal students. Not all students are moving toward becoming more multiculturally aware; some aboriginal students may be moving toward concentration on First Nations peoples and issues. In keeping with the developments of their communities, many aboriginal students are striving to develop an enhanced sense of group identity, not to recognize individual differences. The direction for growth is opposite for many non-aboriginal students, who want an understanding of cross-cultural or multicultural concepts.

It seems that both distinctive and integrative approaches are limited in their utility and validity for any particular aboriginal community. Having an array of program models available across the country, and the capability for aboriginal students to transfer between programs, would allow individual learners to put 
together the most appropriate program for their particular practice needs. In additon, a report card of aboriginal programs that would clearly outline for students the pros and cons of the variety of programs would assist students to make their own judgments.

\section{Curriculum}

One sociological view of curriculum (Lawton, 1975) is that curriculum is essentially a selection from the culture of a society.

Certain aspects of our way of life, certain kinds of knowledge, certain attitudes and values are regarded as so important that their transmission to the next generation is not left to chance in our society but is entrusted to specially-trained professionals (teachers) in elaborate and expensive institutions (schools). Not everything in a culture is regarded as of such importance, and in any case, time is limited, so selection has to be made. Different schools may have different lists of priorities, but all teachers and all schools make selections of some kind from the culture (p.6).

The predominant social work curriculum is selected from mainstream Canadian culture. From the aboriginal perspective, then, social work is a system imposed as part of colonialism and is not really in First Nations' tradition. A social work history in Canada evolves from the British and American experiences. It does not generally incorporate aboriginal experience.

As with the program models, curriculum developments in aboriginal social work education have followed either distinctive or integrative paths. Integrative approaches are evident in aboriginal social work programs that have accommodated curriculum adaptation to incorporate aboriginal perspectives and content while retaining a core curriculum that remains essentially reflective of the ideas of social work as determined by the Canadian Association of Schools of Social Work (CASSW). Pace and Smith reflect the reality of this challenge in the MicMac B.S.W. program at Dalhousie. In reviewing curriculum, the cultural appropriateness of mainstream theory and values has to be balanced with the need not to create a seemingly 'inferior' program by straying too far from accepted standards of the social work education community. This problem is also enhanced by the desire of some aboriginal students to have a 'non-cultural' degree that is as generally acceptable in practice as any other social work baccalaureate degree. 
Distinctive approaches to curriculum development are not pervasive, but they are increasing in visibility. The concept of the medicine wheel for example, came from, and is being developed for, social work curriculum by some aboriginal peoples.

This issue of academic standards and cultural relevance also poses an ethical challenge to social work educators. Content selection, even fundamental social work concepts exemplify this issue. A concept is "a rule of judging or acting, a prescription for organizing the materials of experience so as to be able to go on about our business" (Kaplan, 1979, p. 9). Concepts bring discipline to one's thinking about the world, the reality of social work practice. Concepts judge; they organize experience in a particular way, often in a particular cultural way. For example, science as a concept encompasses particular attributes of science. These do not necessarily reflect aboriginal concepts of science. Colorado and Collins (1985) describe an aboriginal science that incorporates such attributes as spirituality, community control and subjectivity. The question arising from such an example is: Is it appropriate or even ethical to teach concepts to aboriginal students that do not help them deal with their reality and which may in fact hinder them in this regard?

Not all social work concepts are incompatible with an aboriginal context, however. For example, an ecological systems perspective has been found useful as a conceptual framework for social work practice with aboriginal communities (Kelley, McKay \& Nelson, 1985).

Educators have a lot yet to learn about the relevancy of their favourite content to an aboriginal community. They also have a lot to discover about new concepts that assist social workers to practise effectively in aboriginal communities. The opportunity to address these is in the classroom. Teaching models can provide the chance to assess traditional social work knowledge, skills and values as well as discover the knowledge, skills and values held by First Nations and aboriginal students.

\section{Models of Teaching}

Much of social work education relies on a teaching model that encourages students to incorporate material into their professional practice. Curriculum, lectures, class exercises, assignments and examinations are designed to facilitate the integration of theory and practice. Such a model assumes that the material presented (theories, concepts, skills) is generally better or more useful than material that is not presented. It assumes a commensurate goodness in the knowledge offered. As discussed previously, the appropriateness of social work 
knowledge for aboriginal communities cannot be assumed; therefore, alternative teaching models need to be explored.

The alternative proposed in this paper is an interface teaching model. Such teaching is designed simply to offer material and ideas to students. It facilitates the presentation of material in a detached manner, separate from the presenter and the student, as a curiosity with which to wrestle. Such a model assumes that there is no magic or relative importance to any theory, concept or skill. Critical to an interface model though, is the balance this detachment has with respect for ideas and for the context of ideas. Freire (1970) says that the task of the teacher is to represent the universe to the people from whom he or she first received it, and to represent it not as a lecture but as a problem. This notion is akin to the interface model of teaching. A concept or piece of content is presented as a problem, a question to be wrestled with, not a piece of knowledge to be banked. It is discovering with students, "to come to know with them the reality which challenges them" (p. 101).

An example of how the interface model translates to the classroom may be useful at this point. In teaching a particular class of students, various models of helping, several persons' views are put forth; for example, Egan's (1982) planned change model is outlined as one model that some social workers find useful, and students are asked to provide the illustrations of its applications. Then, the medicine wheel is outlined as an example of what some aboriginal peoples believe, and again students are asked to illustrate the model. Space is provided for the class members to put forth their ideas of helping and these models are again illustrated by the group; and so on. The critical features of this interface teaching model are the respectful presentation and consideration of ideas, the using of students to apply concepts to practice, and the provision of space, both in time and curriculum, to ensure that individual students' concepts are given equivalent opportunity and treatment.

From the curriculum through to the classroom, the social work educational experience for aboriginal students can be alienating. Brundage and MacKeracher (1980) state that one of the principles of learning is that "part of the adult learners' past experience is organized and integrated into his self-concept and self-esteem, the adult learner needs to feel his past experience is respected and valued by others" (p. 98). Aboriginal learners may find themselves placed in a learning environment where their past and cultural experience are not valued by the educational institution. While their cultural experience may be seen as romantic or interesting, it is not necessarily valued or respected. For the non-aboriginal teacher, the experience of having aboriginal students in 
the class can be uncomfortable. Overcompensation for aboriginal students, unease over potential conflict or unintended racism, uncertainty of the relevance of material or discomfort with personal awareness of aboriginal issues are just a few of the reactions that a non-aboriginal teacher may experience. Alternative teaching methods, such as the interface model, need to be designed to provide opportunities to address these issues collaboratively with students and teachers.

Part of discovering alternative teaching methods is understanding the nature of andragogy and its application to aboriginal learners. What truly distinguishes andragogy from pedagogy is the focus on self-directed learning and away from teacher-directed learning. Jarvis (1987) further distinguishes between the learning of adults and children on the basis of the social status of the learner, rather than age or intrinsically different forms of learning. This viewpoint begins to recognize the power inherent in education, between teacher and student, and between facilitator and learner. The role of power is also seen in the issues of governance of aboriginal communities. The question of where power lies and how power is used between governments is becoming a focus in the development of self-governing aboriginal communities. An understanding of the power relationship between aboriginal students and mainstream educational institutions (and their faculty) is fundamental to developing appropriate teaching models.

A further premise in andragogy is that adults are social beings, products of history and culture; that is, adults are contextually located (Brookfield, 1986). This view has implications for how aboriginal students are taught in the classroom. Their context is different from that with which many teachers are familiar; yet in the nurturing of social work professionals, how can the qualities of self-determination, self-government and self-education or self-directed learning be fostered, given the general unawareness of the context of the aboriginal experience?

Self-direction in learning is not a set of techniques that can be applied within a context of objectives and evaluative criteria that are determined by others...Self-directed learning in adulthood... is... a matter of learning how to change our perspectives, shift our paradigms, and replace one way of interpreting the world by another. (Brookfield, 1986, p. 19).

Brookfield states that one can only be self-directed within one's experience and self-imposed limits. Learners cannot conceive of alternate frameworks; such learning (e.g., a change in paradigm) is induced externally. 
Mezirow (1981) talks about this change in framework as a process of perspective transformation. That is, one goes through a series of role transitions as one develops a new perspective. He says that "individuals may be assisted to convert these transitions into transformations of perspective" (p. 11).

The current transformation that occurs for many aboriginal students in non-aboriginal institutions is not always what is desired by aboriginal communities. They send their young people off to university to be educated so that they will come home to work. But the young people are exposed to different perspectives while at school and may be thereby distanced from home and from communication with their relatives. Missouri says "when a meaning perspective can no longer comfortably deal with anomalies in a new situation, a transformation can occur. Adding knowledge, skills or increasing competencies within the present perspective is no longer functional" (p. 105).

This is what happens to learners. The non-aboriginal educational system has given them new knowledge, skills and ways of thinking and has facilitated a transformation of perspective. For aboriginal students, however, it has not given energy into valuing their cultural perspective such that it is coherent with their transformed view. Some students are able to weld their old view with the new in the manner intended by Mezirow's concept. Others, however, are overwhelmed with the new view and their transformation is incongruent with the one left behind.

Daloz (1986) talks about personal development as the construction of more elaborate maps or perspectives.

The task facing both sexes is to reframe and understand in a radically new way the meaning of the world they once knew. This does not mean that the old world has been abandoned; rather it has been incorporated into a broader awareness of its place. It is seen in a new way. (p. 26)

The challenge for social work educators is to facilitate the education and transformation of aboriginal students in a way that is useful, relevant and valuable for aboriginal communities. Recognising that the target of education is communities, not individuals, is the beginning of this transformation of value perspective for educational institutions.

How can educators foster these goals, given that their experience may not include culturally relevant views? Belenky and her colleagues (1986) introduce the notion of teacher as participant observer (along the lines of cultural anthropologists). This may be relevant for teachers in cross-cultural settings. They say that "teaching can be simultaneously objective and personal" (p. 224). 
Freire discusses the role of objectifying one's experience in order to understand it. "Subjectivity and objectivity thus join in a dialectical unity producing knowledge in solidarity with action, and vice versa" (p. 22). Teachers can interpret this by recognizing that in order for learners, whether students or teachers, to understand themselves they must objectify their experience.

Daloz (1986) has a similar view of teaching. "Education is something we neither give nor do to our students. Rather, it is a way we stand in relation to them" (p.xv). An alternative teaching model such as an interface model highlights the importance of the positioning of teacher and material. It also recognises the value of space and silence in a curriculum, as a means of allowing aboriginal knowledge and perspectives to be offered by students.

Effective teachers in such cross-cultural environments have the opportunity to be facilitators of useful transformations. These teachers, aboriginal and non-aboriginal, can act as translators in the education system. Translators are the boundary people sitting on the edges of different systems. They find themselves acting as representatives of their culture or profession. This role is more than liaison between cultures; it is one of facilitating transformation of both aboriginal and non-aboriginal systems.

The translator role includes the function of mediation between two cultural views of knowledge. Mediation is guided learning and a mediator is a bridge or a designer of bridges. Mediation is an act of language, a deep engagement of listening, feeling, attending, and expressing in ways that are useful to learning (Carr, 1985). The field of social work has the opportunity to lead in cross-cultural education since social work skills are compatible with mediation skills. Learning to apply these skills in the classroom is the challenge for social workers. Teachers who can act as translators and mediators between cultural views of knowledge will play a critical role in the development of aboriginal social work education in the next few years.

A potential benefit will be mutuality in the transformation these teachers foster as aboriginal communities develop self-governing communities and as schools of social work seek to assist them through aboriginal social work education initiatives. Aboriginal communities as well as mainstream Canadian social work values, knowledge and skills have the opportunity to be reciprocally transformed.

\section{Notes}

$122 \%$ of those admitted to the U.Vic. on-campus BSW program in 1990 identified themselves as aboriginal people. 


\section{References}

Belenky, M.F., Clinchy, B.M., Goldberger, J.M., \& Tarule, J.M. (1986). Women's ways of knowing. New York: Basic Books.

Brookfield, Stephen. (1986). Understanding and facilitating adult learning. San Francisco: Jossey-Bass.

Brundage, D.H., \& MacKeracher, D. (1980). Adult learning principles and their application to program planning. Toronto: Ontario Ministry of Education.

Carr, David. (1985). Mediation as a helping presence in cultural institutions. In Sandra Rosenblum, (Ed.), Involving adults in the educational process. San Francisco: Jossey-Bass.

Cassidy, Frank, \& Bish, Robert. (1989). Indian government: Its meaning in practice. Victoria: Oolichan Books and Institute for Research on Public Policy.

Castellano, Marlene Brant, Stalwick, Harvey, \& Wein, Fred. (1986). Native social work education in Canada: Issues and adaptations. Canadian Social Work Review, 166-184.

Colorado, Pam, \& Collins, Don. (1987). Western scientific colonialism and the re-emergence of native science. Practice: The Journal of Politics, Economics, Psychology, Sociology and Culture, 50-65.

Daloz, Larent. (1986). Effective teaching and mentoring. San Francisco: Jossey-Bass.

Douse, Pat, \& Green, Norma. (1990). Unpublished paper.

Egan, Gerald. (1982). The skilled helper: Model, skills and methods for effective helping, second edition. Monterey, California: Brooks/Cole Publishing.

Freire, Paulo. (1970). Pedagogy of the oppressed. New York: Seabury Press.

Jarvis, Peter. (1987). Adult learning in the social context. New York: Croom Helm.

Kaplan, Abraham, as quoted by Roberts, Hayden. (1979). Community development. Toronto: University of Toronto Press.

Kelley, Mary Louise, McKay, Sharon, \& Nelson, Connie H. (1985). Indian agency development: an ecological practice approach. Social Casework, 594-602.

Lawton, Denis. (1975). Culture and the curriculum. London: Routledge and Kegan Paul. Mezirow, Jack. (1978). Perspective transformation. Adult Education, 100-110.

Mezirow, Jack. (1981). A critical theory of adult learning and education. Adult Education, 3-24.

Pace, Jacqueline, \& Smith, Ann. (1990). Native social work education: Struggling to meet the need. Canadian Social Work Review, 109-119.

University of Victoria, School of Social Work. (May, 1990). A social work degree program for First Nations. 